\title{
UNIDADES DE PAISAGEM COMO CONTRIBUIÇÃO À GESTÃO DAS ÁGUAS: ESTUDO APLICADO NA UNIDADE DE GESTÃO DE RECURSOS HÍDRICOS PARANAPANEMA - BRASIL
}

\author{
Letícia Roberta Trombeta $^{(\mathrm{a})}$, Eduardo Salinas Chávez ${ }^{(\mathrm{b})}$, Antonio Cezar Leal ${ }^{(\mathrm{c})}$, \\ (a) Doutoranda do Programa de Pós-Graduação em Geografia UNESP-Pres. Prudente, leticiaroberta89@ @otmail.com. \\ (b) Faculdade de Ciências Humanas,Universidade Federal da Grande Dourados, esalinasc@yahoo.com. \\ (c) Departamento de Geografia UNESP-Pres. Prudente, Pesquisador Pq/CNPq, cezar@ @ fct.unesp.br.
}

\section{EIXO: BACIAS HIDROGRÁFICAS E RECURSOS HÍDRICOS: ANÁLISE, PLANEJAMENTO E GESTÃO}

\begin{abstract}
Resumo
A delimitação e a cartografia das unidades da paisagem para estudos de territórios extensos, de média a pequenas escalas tem sido frequente, principalmente, pelas vantagens oferecidas pelos Sistemas de Informações Geográficas (SIG) e suas numerosas ferramentas de análise espacial dos fenômenos e processos naturais e antrópicos, juntamente com a melhora e maior divulgação das imagens de satélites e seus produtos derivados. Essas unidades de integração geográfica permitem ter uma visão sistêmica e holística dos componentes físico-geográficos e socioeconômicos como base para a gestão dos recursos hídricos em bacias hidrográficas de grande extensão. Este trabalho visa apresentar as vantagens desse enfoque integrador das paisagens geográficas à gestão hídrica da bacia hidrográfica do Rio Paranapanema, região de grande importância para o desenvolvimento econômico e social dos estados de São Paulo e Paraná, Brasil.
\end{abstract}

Palavras chave: Unidades de paisagem, manejo integrado, gestão das águas, recursos hídricos, Rio Paranapanema.

\section{Introdução}

Durante as últimas décadas, a problemática ambiental deixou de ser um tema exclusivamente acadêmico, mas uma necessidade vital para a sobrevivência da sociedade atual e futura. Diante disso, está a desigualdade na distribuição espacial dos recursos hídricos em nível mundial, sua superexploração e degradação, a escassez de água, a diminuição da sua qualidade e o aumento dos desastres "naturais" associados a eles.

Um exemplo disso, são as inundações, que alteram o funcionamento dos sistemas hidrológicos naturais e o regime hídrico, caracterizando a forma como a humanidade tem se apropriado e gerido os recursos natuais, especialmente a água. Diante desta situação, é necessária a mudança de paradigma na gestão dos recursos naturais, a partir de um enfoque setorial para uma visão mais integrada e sistêmica do ambiente. 
$\mathrm{Na}$ busca de intrumentos de gestão que possibilitem a transversalidade das políticas setoriais, o manejo integrado de bacias hidrográficas é um instrumento de planejamento e gestão adequado, não só permite a gestão equilibrada dos componentes e fenômenos naturais e socioeconômicos presentes na bacia, mas também a integração dos sujeitos sociais e institucionais envolvidos no seu uso e proteção.

As bacias hidrográficas constituem um tipo especial de sistema ambiental ou geossistema, que se define como: um espaço físico organizado de acordo com o escoamento da água na superfície terrestre, cujos limites estão geralmente determinados pelo divisor principal, segundo o relevo e a partir do direcionamento das águas para outro sistema fluvial, como um lago ou o mar (MATEO, 2008a, GONZÁLEZ, 2004, HENDRIKS, 2009, GARCÍA, 2007).

Outros autores as consideram como sistemas complexos, sistemas geográficos ou geossistemas naturais, constituídas pelas relações dinâmicas que ocorrem entre as pessoas e a natureza, no espaço geográfico que elas ocupam (FARIAS et. al., 2015, FROLOVA, 2008).

O estudo das bacias hidrográficas passou de uma simples descrição e análise das suas características hidroclimáticas para um enfoque integrado e mais complexo, no qual evidencia a relação entre a natureza e a sociedade, consolidando nas útimas décadas, o já mencionado, manejo integrado de bacias hidrográficas. Este representa um nível mais profundo de análise deste espaço geográfico definido e que está relacionado com a análise e gestão do território (COTLER, PRIEGO, 2004, LAVRADORSILVA, 2002, MACHADO, 2013).

A partir da análise integrada desta unidade geográfica complexa que é a bacia hidrográfica (MATEO, 2008a), propõe-se uma série de premissas para seu estudo, dentro de uma concepção ambiental e de sustentabilidade, tais como:

- Considerar a bacia hidrográfica como uma totalidade sistêmica, formada pela interação dos componentes e fenômenos naturais, sociais, econômicos, culturais e políticos, que formam diversos ecossistemas, geossistemas e sociosistemas;

- Considerar que estes sistemas na bacia hidrográfica formam unidades de caráter individual que podem ser delimitadas, classificadas e cartografadas no interior da mesma; 
- Considerar que seu planejamento e gestão visam alcançar a sustentabilidade em todas suas dimensões, devendo ter um caráter holístico e prospectivo que responda não só as necessidades objetivas, mas sobre todas as exigências e expectativas das populações locais.

Como unidade espacial, a bacia hidrográfica funciona como sistema complexo, dinâmico e aberto, na qual enfoques integradores no seu estudo, como o ecossitêmico ou das paisagens físico-geográficos, são de grande utilidade, com vistas a obter uma visão integradora da natureza, possibilitando apreender sua integridade sem ignorar sua heterogeneidade espacial, incluindo as modificações antrópicas que nela ocorrem (PRIEGO, ET AL. 2004, GUERRERO, 2007).

Há algumas décadas, as paisagens têm sido consideradas como: sistemas espaço-temporais complexos e abertos, integrados por elementos naturais e antrópicos, que possuem estrutura, funcionamento, dinâmica e evolução particulares que lhes conferem integridade, limites próprios e se constituem em uma asociaciação de objetos e fenômenos que estão em constante e complexa interação e movimento; apresentando uma hierarquização no interior de seus componentes (MATEO, 2008b, BASTIAN, STEINHARDT, 2002, KIYOTANI, 2014, SALINAS, REMOND, 2015, VITTE, 2007, ISACHENKO, 1973).

A singularidade e importância da bacia hidrográfica como unidade de planejamento e gestão é dada por ser uma unidade geográfica natural com condições muito específicas e próprias, entre elas: independência relativa, limites naturais bem definidos e uma dinâmica funcional determinada pela troca de energia e matéria (WORLD VISIÓN, 2014).

\section{A Unidade de Gestão de Recursos Hídricos Paranapanema}

A Unidade de Gestão de Recursos Hídricos Paranapanema (UGRH Paranapanema) abrange 247 municípios e cerca de 4,6 milhões de habitantes. O Estado de São Paulo tem 115 municípios inseridos na bacia e cerca de 1,7 milhões de pessoas e o Estado do Paraná com 132 municípios e 2,9 milhões de habitantes (IBGE, 2010), inseridos integralmente ou parcialmente nesta unidade hidrográfica. A UGRH Paranapanema tem uma área de 106,5 mil km², inserida na Região Hidrográfica do Rio Paraná, tendo como rio principal o Rio Paranapanema localizado entre os dois estados (Figura 1). 

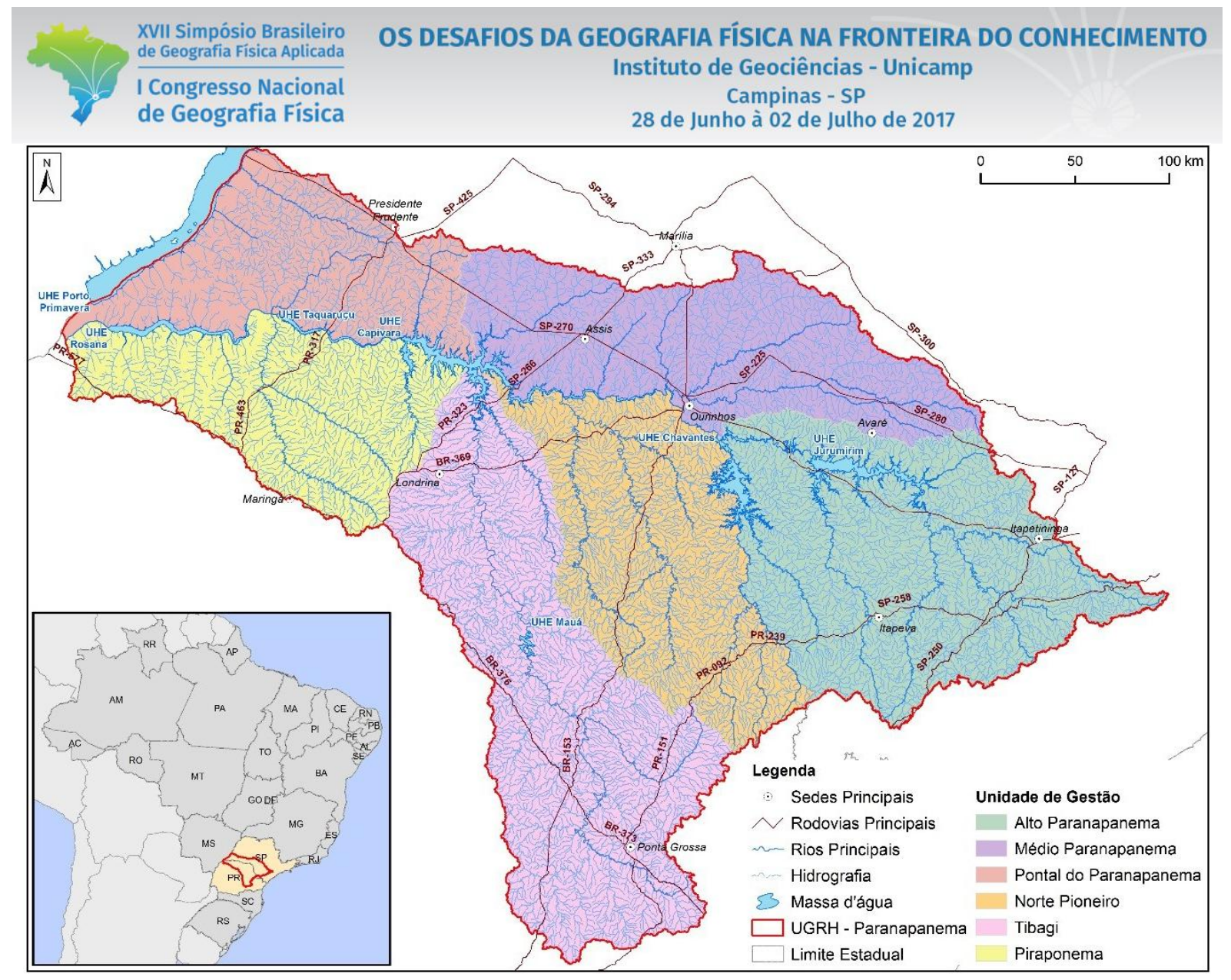

Figura 1 - Mapa de localização da UGRH Paranapanema

Fonte: ANA e CBH-Paranapanema, 2016.

As principais cidades inseridas na UGRH Paranapanema são: Assis, Itapetininga, Ourinhos e Presidente Prudente, na vertente paulista; e, Londrina, Maringá e Ponta Grossa, na vertente paranaense (ANA e CBH-Paranapanema, 2016).

A UGRH Paranapanema foi definida pela Resolução CNRH nº 109 de 2010, que criou as UGRHs dos rios de domínio da União, que de acordo com o Art. $1^{\circ}$ visam "orientar a priorização na implantação de comitês de bacias e impletamentação dos instrumentos da Política Nacional de Recursos Hídricos" (CNRH, 2010a). Com isso, ainda em 2010, foi publicada a Resolução CNRH $n^{\circ}$ 120, que aprovou a proposta de instituição do Comitê da Bacia Hidrográfica do Rio Paranapanema, promovendo a articulação entre a União e comitês de bacias do Estado de São Paulo e do Estado do Paraná, que estão contidos na UGRH Paranapanema.

Art. $2^{\circ}$. A União, os Estados do Paraná e de São Paulo e os comitês de bacias hidrográficas instituídos no âmbito desses Estados, com áreas contidas total ou parcialmente na bacia do rio Paranapanema, articular-se-ão em prol de um Pacto para a Gestão Integrada das Águas da Bacia Hidrográfica do Rio Paranapanema, concomitante com o processo de instalação do CBH Paranapanema, por meio de celebração de um 
acordo para a definição de metas do arranjo institucional, das atribuições compartilhadas e principalmente da garantia de funcionamento do Comitê (CNRH, 2010b).

A composição do Comitê da Bacia Hidrográfica do Rio Paranapanema é dada por representantes da União, dos estados de São Paulo e Paraná, dos municípios constantes da sua área de atuação, usuários das águas e entidades civis de recursos hídricos com atuação comprovada na bacia.

Esta UGRH constitui a área de atuação do CBH Rio Paranapanema e está organizada em seis Unidades de Gestão, que constituem a área de atuação de seis Comitês de Bacias Hidrográficas estaduais, sendo elas: Alto Paranapanema, Médio Paranapanema e Pontal do Paranapanema, no Estado de São Paulo; e, Norte Pioneiro, Tibagi e Piraponema, no Paraná.

\section{Cartografia de paisagens da bacia hidrográfica do Rio Paranapanema}

A paisagem, como categoria de análise da Geografia, oferece suporte à cartografia de síntese para os estudos de ordenamento territorial e/ou ambiental, sobretudo, às atividades de planejamento e gestão do ambiente, reconhecendo que a diversidade paisagística tem importância fundamental no planejamento do território. Além disso, subsidia a tomada de decisões pautadas no conhecimento da diversidade de ambientes em uma determinada localidade (CAVALCANTI, 2014).

A Cartografia de Paisagens é uma atividade ligada à Geografia, uma vez que sua execução necessita de uma série de conhecimentos distintos que encontram na Geografia física seus principais subsídios, a exemplo da morfologia dos solos, do inventário florestal e do mapeamento geomorfológico (CAVALCANTI, 2014, p.6).

A cartografia da paisagem tem sido estudada em diferentes escalas por diversos autores (MARTINELLI e PEDROTTI, 2001; SALINAS e QUINTELA, 2001; RAMÓN, SALINAS e REMOND, 2009), que elaboraram diversos esquemas para delimitação das unidades para serem representadas em um mapa final da paisagem de um determinado território (ABALAKOV AND SEDYKH, 2010; CAVALCANTI, ET AL., 2010; MÜCHER, ET AL., 2010; SALINAS, ET AL., 2013).

Esta cartografia é realizada considerando diversos pressupostos que são esboçados no procedimento metodológico (Figura 2), o qual apresenta os passos necessários para obter o primeiro mapa de unidades morfológicas do relevo, etapa fundamental para a elaboração do mapa de paisagem de um território. Pretende-se esgotar as possibilidades metodológicas, usando como ferramenta o Sistema de Informações Geográficas (SIG) ArcGis 10.2®, atravéz da execução de tarefas para análise espacial, com ferramentas que tem capacidade de geoprocessar modelo de dados raster e matricial, realizar modelagens e análises diversas. 


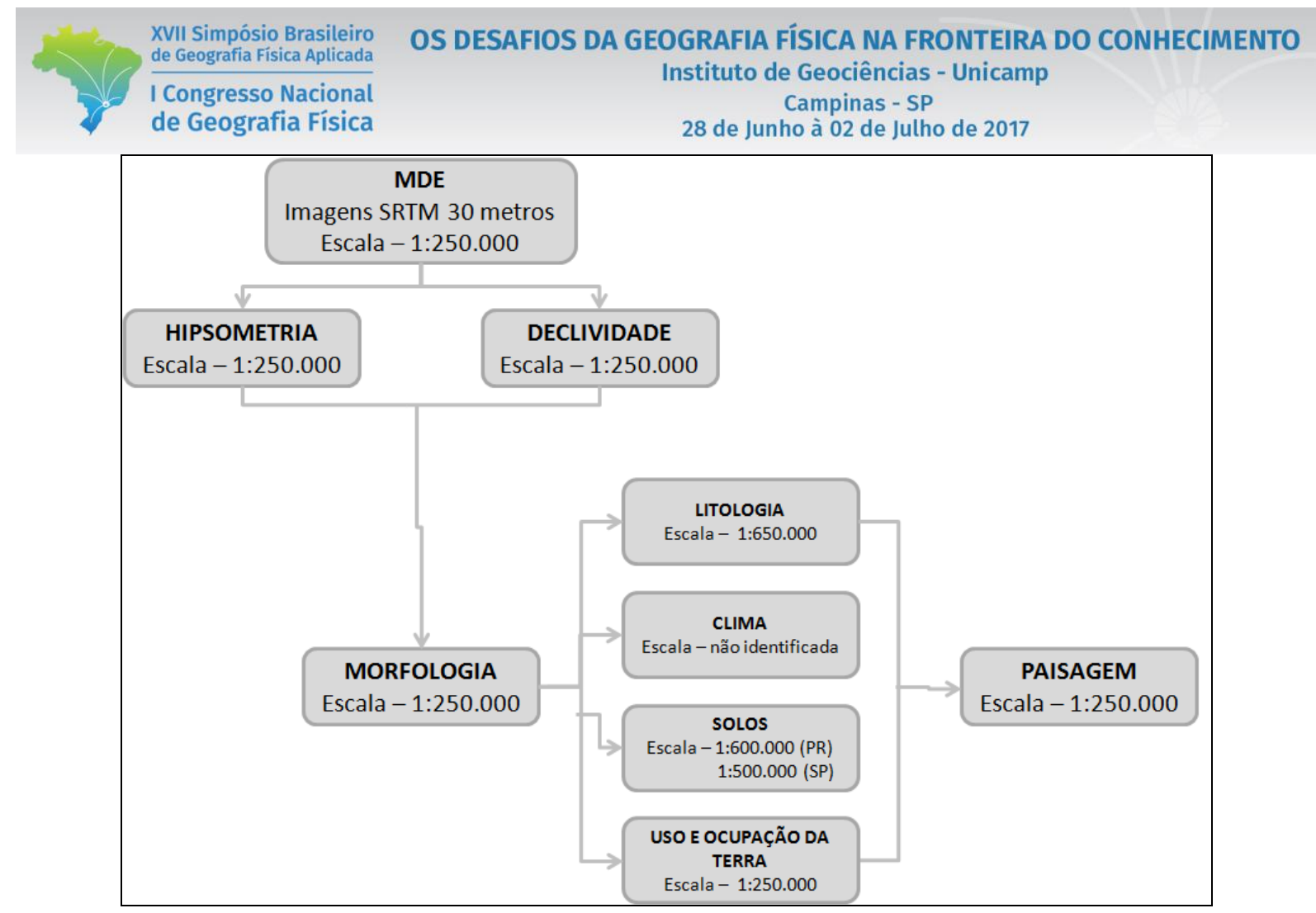

Figura 2 - Organograma do processo de elaboração do mapa de paisagem.

A primeira etapa foi elaborar o Modelo Digital de Elevação (MDE), construído a partir do mosaíco das imagens de radar SRTM (Shuttle Radar Topography Mission) já tratadas pelo Banco de Dados Geomorfométricos do Brasil do INPE (Instituto Nacional de Pesquisas Espaciais), com resolução espacial de 30 metros. Este MDE, após processamento, deu origem aos mapas de Hipsometria e Declividade, ambos na escala de 1:250.000.

A partir do cruzamento espacial entre os mapas de Hipsometria e Declividade foi elaborado o mapa de Morfologia, que considera as principais variáveis do relevo, que, posteriormente, foi cruzado com as informações de Litologia, dando origem ao mapa de Geoformas. Este último teve cruzamentos realizados com os mapas de Clima, Solos e Uso e Ocupação da Terra, subsiando a delimitação das unidades de paisagem.

\section{Paisagem como contribuição à gestão hídrica de bacias hidrográficas}

A análise da paisagem oferece subsídios à gestão hídrica de bacias hidrográficas, a qual tem como propósito fundamental articular a organização espacial e ambiental, para que possa estar em equilíbrio no ambiente, bem como priorizar a racionalidade e a estabilidade dos aspectos do espaço natural e das paisagens de diferentes áreas. As unidades da paisagem podem ser utilizadas como subunidades de 


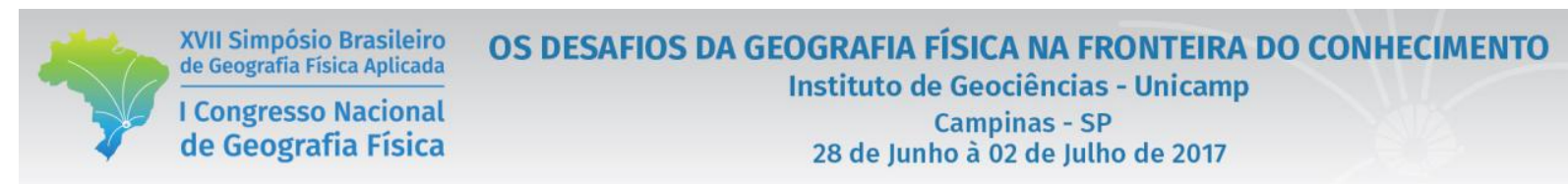

planejamento e gestão territorial, servindo de apoio às atividades de planejamento ambiental, inclusive no âmbito das bacias hidrográficas (RIBEIRO, 2012). Elas resultam da síntese dos elementos físicogeográficos e socioeconômicos, definindo as homogeneidades existentes no espaço. Cada unidade da paisagem, com o detalhamento das suas características, pode servir como um território de intervenção de ações para melhoria da qualidade ambiental.

De acordo com Dibieso (2013, p.223), a fim de contribuir com o planejamento ambiental e a gestão da bacia hidrográfica é realizada a

Compartimentação da paisagem em segmentos denominados unidades de paisagem ou ambientais. Para estas unidades devem ser estabelecidas diretrizes, metas e normas específicas para as diferentes porções do território, buscando garantir maior eficácia na recuperação, conservação e proteção dos recursos hídricos.

As unidades da paisagem ao serem sintetizadas revelam a situação do território, a partir da análise conjunta de diversos aspectos naturais e, principalmente, a herança da ação antrópica marcada na paisagem. Com isso, a elaboração das unidades da paisagem permite identificar áreas homogêneas na bacia hidrográfica, por exemplo, a partir da combinação de diversos elementos naturais e sociais que fazem parte de um conjunto tão complexo, procurando individualizá-las.

As unidades ambientais de planejamento são individualizadas a partir da "semelhança" das suas características, permitindo sua individualização. Esta subdivisão da bacia hidrográfica permite a definição de um padrão para as unidades com potencialidades, fragilidades e problemas ambientais semelhantes [...] Sendo definidas e analisadas como subunidades de planejamento e gestão (DIBIESO, 2013, p. 224).

O estudo das propriedades e características das unidades da paisagem é possível propor um modelo de uso racional e sustentável do espaço geográfico (SALINAS e RAMÓN, 2013).

Para esta análise, é necessário resaltar que, desde meados da década passada, foram aprovados vários instrumentos para a bacia hidrográfica do Rio Paranapanema, com vistas a assegurar sua melhor utilização e proteção. Porém, muitos desses instrumentos eram setoriais, se sobrepõem, sendo elaborados, geridos e administrados pelos três níveis de governo (federal, estadual e municipal).

A visão da maioria desses instrumentos não era integrada, concepção que se buscou superar com o estabelecimento, em 2010, do Pacto para a Gestão Integrada das Águas da bacia hidrográfica do Rio Paranapanema, concomitantemente com o processo de instalação do $\mathrm{CBH}$ Paranapanema e a aprovação do Plano Integrado de Recursos Hídricos da Unidade de Gestão de Recursos Hídricos Paranapanema, em 2016 (PIRH, 2016). 
Embora existam esses instrumentos, a gestão integrada e sustentável da bacia hidrográfica não está garantida por vários aspectos, entre os quais os mais importantes são os seguintes:

- A gestão integrada está em processo de construção entre os entes da federação Brasileira e os comtiês de bacias Hidrográficas com atuação na UGRH Paranapanema, associada a proteção de um recurso, a água, como base para outros recursos naturais, necessitando o fortalecimento de uma visão sistêmica e holística da natureza e da sociedade;

- As unidades propostas para a gestão são subunidades hidrológicas dentro da bacia hidrográfica do Rio Paranapanema, sendo muito extensas e heterogêneas, tanto do ponto de vista natural quanto socioeconômico. Dessa forma, nos planos de bacias hidrográficas estas Uidades são subdividadas, tendo sido criadas unidades de planejamento menores;

- Existe sobreposição de instrumentos de planejamento e gestão na bacia hidrográfica por sua situação geográfica, inserida em dois estados e com 247 municípios com diversos interesses econômicos, sociais e políticos, os quais devem ser compatibilizados, em um processo amplo de pactuação entre os vários setores;

- A grande diversidade natural, econômica e social existente na bacia hidrográfica requer análise detalhada e permanente das estratégias, planos e programas desenvolvidos para garantir a sua gestão integrada e sustentável;

- A ausência, nos trabalhos realizados até o momento, de definição de unidades da paisagem, em várias escalas, que integram a natureza e a sociedade e permitam trabalhar com escalas mais detalhadas, para fundamentar o prognóstico e as propostas de utilização e proteção dos diversos espaços e recursos da bacia hidrográfica.

Com vistas a realizar uma primeira análise desta situação, foi elaborado o Quadro 1, que mostra a relação entre as unidades de gestão propostas pelo Plano Integrado de Recursos Hídricos da Unidade de Gestão de Recursos Hídricos Paranapanema (PIRH, 2016) e as unidade de paisagem cartografadas para este estudo, indicando, de forma preliminar, alguns aspectos desta relação, suas características e problemas ambientais principais.

O Quadro 1 não esgota as análises que serão realizadas a partir do mapa de paisagem e a determinação de diversos índices geoecológicos, que possibilitarão estabelecer uma série de 
recomendações para as unidades de gestão propostas para esta bacia hidrográfica, considerando a conservação e uso sustentável dos recursos naturais.

Tabela 1 - Relação entre as unidades de paisagem de segunda ordem e as unidades de gestão estabelecidas pelo Plano Integrado de Recursos Hídricos da Unidade de Gestão de Recursos Hídricos Paranapanema.

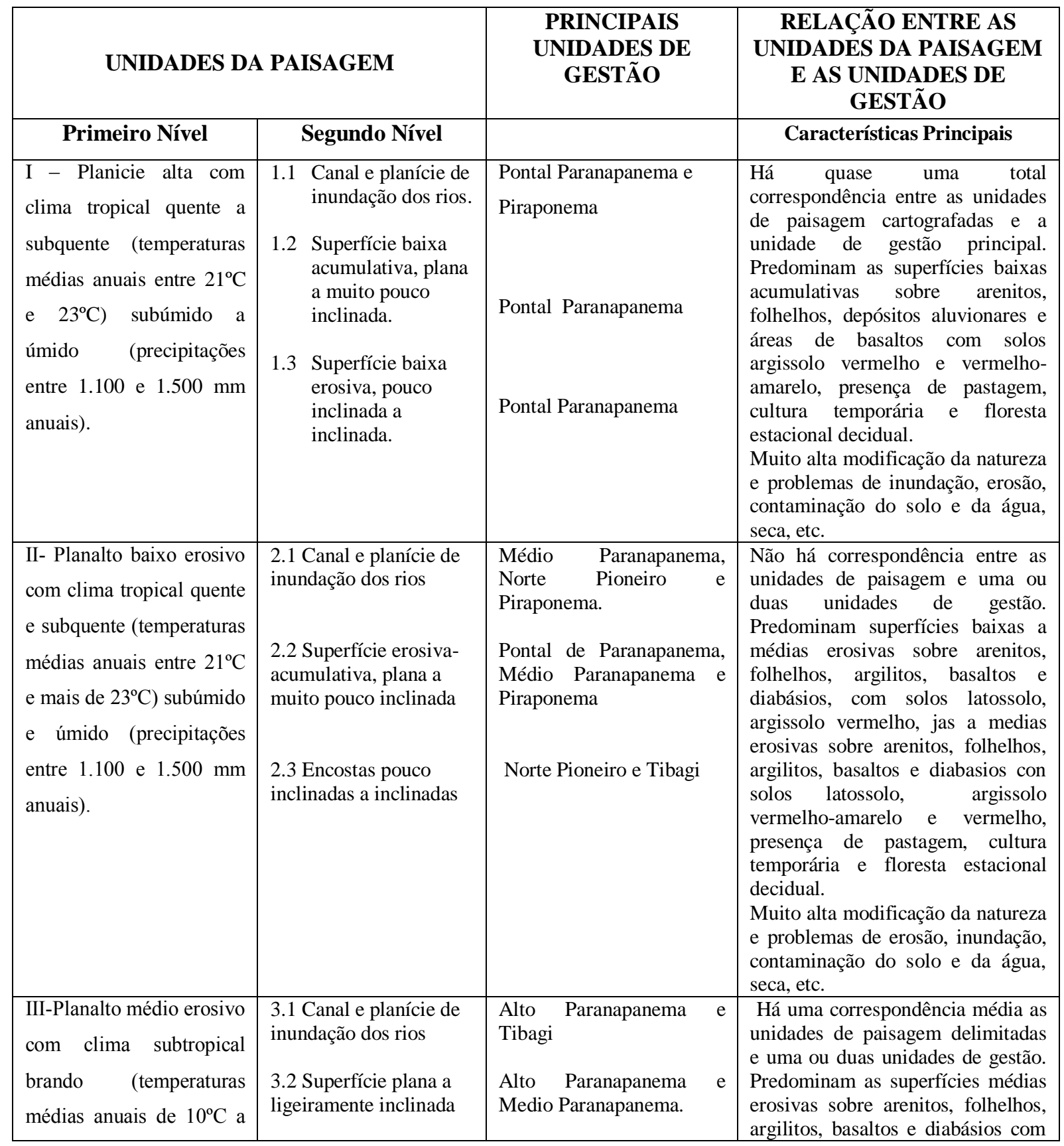




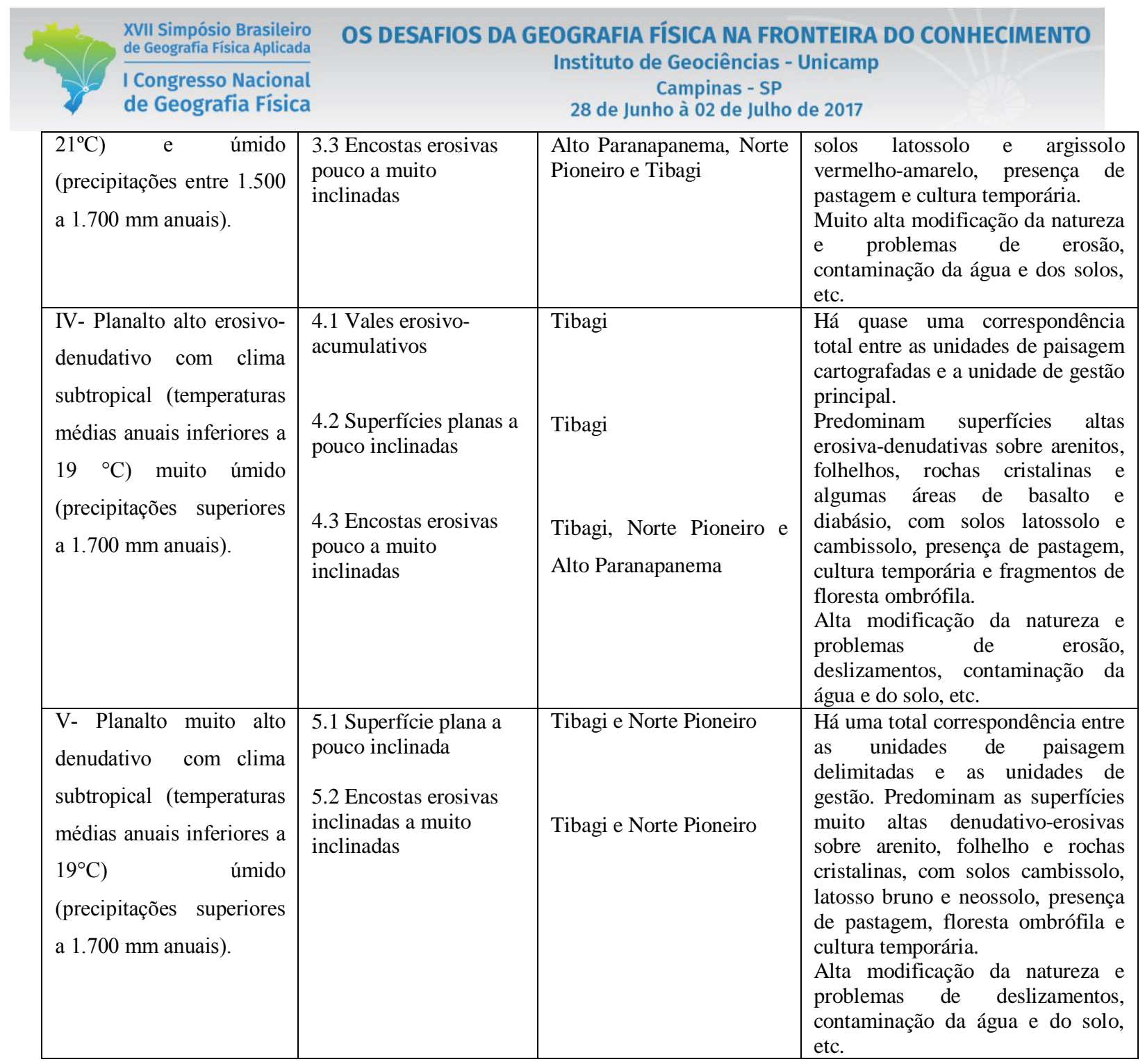

\section{Considerações Finais}

O inadequado uso da água como recurso natural renovável, tem levado muitas regiões e populações do planeta ao limite, o que torna cada vez mais necessária uma visão integrada e sistêmica deste recurso e sua relação com a sociedade e as múltiplas atividades humanas que dela dependem.

Nesse contexto, o manejo integrado de bacias hidrográficas coloca-se como opção apropriada para garantir o uso sustentável da água e a integração de políticas públicas e privadas na bacia hidrográfica do Rio Paranapanema, superando o enfoque setorial e incompatível com este território.

A cartografia de paisagens, com o estabelecimento de unidades de integração sistêmica dos componentes e processos naturais e das atividades humanas que ocorrem na bacia hidrográfica, pode considerar a base espacial sobre a qual serão elaboradas propostas de uso e gestão, não apenas da água, mas para todos os recursos naturais e humanos da área, com enfoque holístico e sustentável. 
Para analisar as possibilidades oferecidas pela concepção integradora da paisagem na Gestão Integrada de Bacias Hidrográficas foi escolhida a bacia hidrográfica do Rio Paranapanema, que representa uma das bacias mais importantes do país, especialmente para os estados de São Paulo e Paraná, os quais concentram uma grande população e que sofreram um intenso desenvolvimento econômico ao longo do último século.

A elaboração do mapa de paisagem da bacia hidrográfica do Rio Paranapanema se deu a partir de informações obtidas no Plano Integrado de Recursos Hídricos da Unidade de Gestão de Recursos Hídricos Paranapanema (PIRH, 2016) e de estudos realizados pelo Grupo de Pesquisa em Gestão ambiental e Dinâmica Socioespacial (GADIS). Foram utilizadas, pincipalmente, as ferramentas existentes em ambiente SIG, no software ArcGis $10.2 \AA$, com enfoque desenvolvido durante vários anos entre o grupo de pesquisa e a Universidade de Havana.

Assim, foram delimitadas, com caráter tipológico, cinco unidades da paisagem de primeiro nível, de acordo com as grandes morfoesculturas do relevo e suas características climáticas, 35 de segundo nível a partir da delimitação da morfologia e das geoformas e 130 unidades nos dois últimos níveis da classificação, considerando os solos, a vegetação natural e o uso e ocupação da terra atual.

\section{Bibliografia}

ABALAKOV, A. D.; SEDYKH, S. A. Regional-typological study and mapping of geosystems: analysis of the implementation, Geography and Natural Resources 31 p. 317-323, 2010.

AMOROS, C.; PETTS, G.E. Hydrosystemse fluviaux, Paris-Milan-Barcelonne-Bonne: Masson, 1993.

ANA, Agência Nacional de Águas; CBH-Paranapanema, Comitê da Bacia Hidrográfica Rio Paranapanema. Plano Integrado de Recursos Hídricos da Unidade de Gestão de Recursos Hídricos Paranapanema. ANA e CBHParanapanema, 2016.

BASTIAN, O.; STEINHARDT, U. Development and Perspectives of Landscape Ecology, Dordrecht: Kluwer Academic Publishers, 2002.

CAVALCANTI, L. C. S. Cartografia de paisagens: fundamentos. São Paulo: Oficina de Textos, 2014.

CAVAlCANTI, L. C. S.; CORREA, A. C. B.; ARAÚJO FILHO, J. C. Fundamentos para o mapeamento de geossistemas: uma atualização conceitual, Geografía (Rio Claro, Impresso), v. 35, p. 539-551, 2010.

COTLER, H.; PRIEGO, A. El análisis del paisaje como base para el Manejo Integrado de cuencas: el caso de la cuenca Lerma-Chapala, En: Cotler, H. (Compiladora), El manejo integral de cuencas en México: estudios y reflexiones para orientar la política ambiental, INE- SEMARNAT, México, 2004, p. 63-74.

FARIAS J. F.; SILVA, E. V. DA Geoecologia das paisagens e planejamento ambiental: teoria e metodologia aplicadas na bacia hidrográfica do rio Palmeira/Ceará, Em: Bacias hidrográficas - métodos e técnicas de estudo, usos, ocupação e conflitos no Espaço Geográfico, XVI Simpósio de Geografia Física e Aplicada, Teresina, Piauí, 28 de junho a 04 de julho de 2015.

FROLOVA, M. El estudio de los paisajes del agua en una cuenca vertiente: Propuesta metodológica, Revista de Estudios Regionales, No 83, 2008, p.21-47. 
GARCÍA, J. M. Aplicación del enfoque ecosistémico a la gestión integrada de los recursos hídricos. Aproximación al caso cubano, Voluntad Hidráulica, No. 99, Año XLV, 2007, p. 18-29

GONZALEZ, J. I. El Manejo de Cuencas en Cuba: actualidades y retos En: Cotler, H. (Compiladora), El manejo integral de cuencas en México: estudios y reflexiones para orientar la política ambiental, INE- SEMARNAT, México, 2004, p. 21-40.

GUERRERO, E. El Enfoque Ecosistémico aplicado a la gestión del agua. Una perspectiva desde América Latina, En: ANDRADE, A. (Editora) Aplicación del Enfoque Ecosistémico en Latinoamérica, Bogota: CEM - UICN, 2007.

HENDRIKS, J. Conceptos e instrumentos para la gestión integrada de cuencas hidrográficas. La experiencia de la Autoridad Autónoma de Cuenca Hidrográfica Chira-Piura, 2009, p. 1-24

ISACHENKO, A. G. PrincipIes of Landscape Science and PhysicaI Geographic Regionalization, Melbourne: University Press, 1973.

KIYOTANI, I. O conceito de paisagem no tempo, Geosul, Florianópolis, v. 29, n. 57, p. 27-42, 2014.

LAVRADOR-SILVA, A. Avaliação das Paisagens da bacia hidrográfica da Ribeira de Colares. Estudo geográfico e de Percepção ambiental, Finisterra, XXXVII, 74, 2002, p. 185-189.

MACHADO, G. Por uma territorializacao da bacia hidrográfica, En: SAQUET, M.A. (Coordinador), Estudos territoriais na ciência geográfica, São Paulo: Outra expressões 2013, p.107 - 128.

MARTINELLI, M.; PEDROTTI, F. A cartografía das unidades de paisagem: questões metodológicas, Revista do Departamento de Geografía-USP, n.14, p. 39-46, 2001.

MATEO, J. Fundación teórico-metodológica, En: MATEO, J. (Coordinador) Estructura geográfico-ambiental y sostenibilidad de cuencas hidrográficas urbanizadas, La Habana: Editorial Feliz Varela, 2008a.

MATEO, J. Geografía de los Paisajes, Primera Parte. Paisajes Naturales, La Habana: Editorial Universitaria, 2008b.

MÜCHER, C. A.; KLIJN, J. A.; WASCHER, D. M.; SCHAMINÉ, J. H. J. A new European landscape classification (LANMAP): a transparent, flexible and user-oriented methodology to distinguish landscapes, Ecological Indicators 10, p. 87-103, 2010.

PRIEGO, A.; MORALES, H.; ENRIQUEZ, C. Paisajes Físico- Geográficos de la Cuenca Lerma-Chapala, México. Gaceta ecológica 71, 2004, p.11-22.

RAMÓN, A. M.; SALINAS, E.; REMOND, R. Diseño Metodológico para la Elaboración de Mapas de Paisajes con el Uso de los SIG: Aplicación a la cuenca alta del río Cauto, Cuba, Geografía y Sistemas de Información Geográfica (GeoSIG) Año 1, Número 1, p. 95-108, 2009.

RAMÓN, A. M.; SALINAS, E. Propuesta metodológica para la delimitación semiautomátizada de unidades de paisaje de nivel local, Revista do Departamento de Geografía -USP, Volume 25, p. 3- 22, 2013.

SALINAS, E.;RAMÓN, A. Propuesta metodológica de la delimitacion semi automátizada de unidades de paisaje de nível local. Revista do Departamento de Geografia, v.25, p.1-19, 2013.

SALINAS, E.; GARCÍA, A. E.; MIRAVET, B. L.; REMOND, R.; CRUAÑAS, E. Delimitación, Clasificación y Cartografía de los Paisajes de la cuenca Ariguanabo, Cuba, mediante el uso de los SIG, Revista Geográfica del IPGH, No. 154 julio-diciembre, p. 9-30, 2013.

SALINAS, E.; QUÍNTELA, J. Paisajes y ordenamiento territorial: obtención del mapa de paisajes del estado de Hidalgo en México a escala media con el apoyo de los SIG, Alquiba, Revista de Investigación del Bajo Segura, $\mathrm{n}$. 7, p. 517-527, 2001.

SALINAS E.; REMOND, R. El Enfoque Integrador del Paisaje en los Estudios Territoriales: Experiencias Prácticas, En: GARROCHO, C.; BUZAI, G. (Editores) Geografía Aplicada en Iberoamérica: avances, retos y perspectivas, México, p. 503-543, 2015.

VITTE, A. C. O Desenvolvimento do Conceito de Paisagem e a sua inserção na Geografia Física, Mercator Revista de Geografía da UFC, v. 6, n. 11, p.23-38, 2007. 
WORLD VISIÓN Manual de Manejo de Cuencas, Módulo I-Conceptos básicos de Cuencas. Costa Rica, 2014, 28 p. 